\title{
Mindfulness and psychological health in practitioners of Japanese martial arts: a cross-sectional study
}

\author{
Hiromitsu Miyata* (D), Daisuke Kobayashi, Akifumi Sonoda, Hibiki Motoike and Saki Akatsuka
}

\begin{abstract}
Background: Empirical data have suggested that mind-body practices that originated in Eastern traditions can cause desirable changes to psychological traits, the brain, somatic physiological functions, etc. Martial arts in Japan refer to the physical/mental practices that were developed based on historical combat techniques. Today, martial arts are considered activities that seek embodiment and/or mind-body unity, as well as sports. Empirical studies involving practitioners of Japanese martial arts to date remain scarce.
\end{abstract}

Methods: We conducted a questionnaire survey using a cross-sectional design to examine whether the practice of martial arts based on Japanese traditions are associated with mindfulness and psychological health. Participants included a population of practitioners of martial arts with a practice period of 0.6-35.0 years, and non-practitioners matched for demographic variables.

Results: Compared with the non-practitioners, the practitioners of martial arts had significantly higher scores for mindfulness and subjective well-being and lower scores for depression. Among the practitioners of martial arts, a longer period of practice or a higher frequency of daily practice significantly predicted higher mindfulness and psychological health.

Conclusions: The results obtained are consistent with those previously obtained for other populations of Japanese contemplatives, and support the view that practice of multiple Eastern mind-body practices might be associated with similar desirable psychological outcomes. A cross-sectional design has limitations in that it is difficult to determine the effect of continued practice, so that a longitudinal study that follows the same practitioners over time is desired in the future enquiry.

Keywords: Martial arts, Dispositional mindfulness, Subjective well-being, Depression, Long-term practice, Japanese

\section{Background}

Increasing amounts of empirical data during recent decades have demonstrated that mind-body practices that originated in Eastern traditions including Buddhist meditation can cause desirable changes to psychological traits, the brain, somatic physiological functions, etc. (for reviews see $[1,2])$. As Yasuo Yuasa noted, Eastern mind-

\footnotetext{
* Correspondence: miyata@waseda.jp

Faculty of Letters, Arts and Sciences, Waseda University, 1-24-1 Toyama, Shinjuku-ku, Tokyo 162-8644, Japan
}

body theory have not only considered body and mind as one, but also sought for mind-body integration and unity through physical and mental practices [3]. In Japan, such mind-body unity has traditionally referred to as "ShinShin Ichinyo (body and mind as one)." In addition, mindfulness has its origins in the Early Buddhism, and today refers to paying attention to one's moment-tomoment awareness in nonjudgmental and nonreactive ways. The idea of mindfulness has proven effective in elucidating the psychological, physiological, and 
neurocognitive correlates of mind-body and/or contemplative practices in scientific and clinical contexts. Interventions based on mindfulness have been applied to various clinical and educational settings (for reviews see $[4,5])$. For example, mindfulness-based stress reduction (MBSR) program developed by Jon Kabat-Zinn has been shown to reduce psychological symptoms in patients with chronic pain [6,7]. Mindfulness-based cognitive therapy (MBCT) program has applied mindfulness to prevent the relapse of depression [8]. .b (dot-be) program is a mindfulness program developed for school children [9] and have proven effective for enhancing psychological health outcomes such as reduced stress and anxiety and increased psychological well-being.

Despite this accumulated evidence, in Japan, relatively little empirical data exist regarding practice-induced changes in the psychological status and/or somatic physiological states of practitioners of traditional mindbody and/or contemplative practices. Miyata et al. [10] included practitioners of traditional yoga in Japan whose practice period was 0.3 to 34.0 years and found that the practitioners self-reported higher mindfulness and subjective well-being and lower depression and negative affect compared with non-practitioners. In addition, a longer period and a larger amount of daily yoga/meditation practice were significantly associated with higher mindfulness and psychological health (see also [11]). Miyata and Sasaki [12] studied trainees of the ParkSasaki method of speed-reading, a meditation-based technique in Japan to cultivate efficient reading strategies, and found that the trainees exhibited not only higher reading speeds but also higher mindfulness and psychological health than untrained participants. Among these trainees, a longer period of training and a higher reading speed were associated with higher mindfulness and psychological health (see also [13-15]). Given the consistency of results obtained from multiple populations, an important challenge is to examine the extent to which comparable psychological outcomes are observed for practitioners of various Japanese mind-body practices.

Martial arts in Japan refer to a variety of physical and mental practices that have been developed based on historical combat techniques. Today, martial arts are considered not only sports and/or fighting methods, but also activities that seek to obtain practical understanding of embodiment, mind-body unity, and/or physical and mental health [16]. These characteristics of marital arts are considered to converge with the nature of Zen Buddhism as well as that of mindfulness, and are referred to by the phrase "Ken-Zen Ichinyo (oneness of Zen and swordsmanship)" [17]. For example, karate (empty hand) is a traditional form of martial arts originated in Okinawa, Japan. Traditional karate involves not only body manipulation to efficiently defeat one's opponent with bare hands, but also cultivating awareness to one's breath and body through practice, as with Zen and mindfulness. Karate was later introduced to the mainland of Japan by experts such as Gichin Funakoshi, where elements of sports such as games has been largely incorporated [16]. Based on these historical backgrounds, it seems reasonable to assume that martial arts have similar correlates to mindfulness as well as sports in the context of psychological studies [16].

Empirical studies in recent years have started to demonstrate the effectiveness of interventions based on martial arts in the clinical context. For example, Tai Chi is a Chinese martial art that involves multiple components such as musculoskeletal training and enhancement of both interoceptive and exteroceptive awareness [18, 19]. Burschka et al. [19] studied multiple sclerosis patients and showed that a 6-month Tai Chi intervention was effective in reducing depression and increasing life satisfaction, as well as improving body balance and coordination. Tai Chi interventions have also proven effective in patients with fibromyalgia [20] and rheumatoid arthritis [21]. In Japan, physiological responses during To-ate (remote action), which is a technique to attack an opponent with no physical contact, were investigated in a pair of experts in traditional martial arts and revealed changes in intervals between successive heartbeats (R-R intervals) [22] and alpha phase synchronization [23]. Except for these limited data, no systematic empirical studies have investigated whether and how continued practice of Japanese martial arts may cause desirable changes at the psychological, physiological, or neurocognitive levels.

Thus, in the present study, we conducted a crosssectional questionnaire survey to examine whether and how continued practice of martial arts as well as expertise in martial arts are associated with higher dispositional mindfulness and psychological health outcomes. A cross-sectional design has an intrinsic limitation in that completely excluding alternative explanations is difficult; for example, those with higher mindfulness and psychological health may tend to continue the practice longer ([10, 12]; see also [2]). In addition, comparisons between practitioners and non-practitioners using a crosssectional design have a limitation in that any mental attitudes and/or psychological dispositions that are not considered might potentially increase the probability of practicing marital arts. Nevertheless, determining the psychological status in a population of long-term practitioners in which a systematic empirical survey has just started is undoubtedly beneficial, because such data can be utilized as a premise for subsequent longitudinal studies. 
Accordingly, a population of continued practitioners of martial arts based on Japanese traditions were included in the present study. Specifically, the practitioners belonged to the specific organizations founded by Hiroyuki Aoki, who is one of the representative experts of martial arts in Japan. Hiroyuki's thoughts on martial arts are based on the idea of tenshin, which refers to an energy that is assumed to fill the whole universe. According to Hiroyuki, the purpose of the practice in martial arts is to integrate oneself with tenshin and the great nature, thereby living in harmony with people and the society [24]. For such purposes, practitioners engage in multiple styles of mind-body practices including swordsmanship, karate, bojutsu (art of using sticks as a weapon), as well as their combinations. These styles of practices are considered to have elements comparable to those of sports in that they involve continued physical training, although these practices do not aim to win the games as typical sports do. Besides founding his own method named Shintaido (New Body Way), Hiroyuki also established more modern forms of marital arts such as Kenbu Tenshin Ryu. Despite these apparent novelties, all his practices are totally grounded on the Japan's traditions of marital arts [24]. Given the previous findings obtained from other relevant populations of practitioners in Japan, we expected that more extensive practice and expertise in martial arts would predict higher selfreported mindfulness and more desirable psychological health outcomes such as higher subjective well-being and lower depression.

\section{Methods}

\section{Participants and procedure}

Research design for the present study was generally based on preceding cross-sectional studies involving yoga practitioners [10] and speed-reading trainees [12]. Thirty-three healthy practitioners of martial arts (11 females and 22 males; age 22-69 years; mean age $=44.9$ years, standard deviation $(S D)=12.9$ ) participated as a practitioner group. All these practitioners were members of either a general incorporated foundation or a nonprofit organization, both of which were located in Tokyo, Japan, and were founded by the same originator (Hiroyuki Aoki) to promote multiple styles of martial arts practice based on Japanese traditions. According to the self-reports of these practitioners, 22 held the Dan levels and another six held the Kyu levels within the original grading systems of the organizations. Specific content of their daily practice included swordsmanship, karate, bojutsu, etc. and combinations of these. The practitioners reported that they had practiced martial arts for $0.6-35.0$ years (mean $=14.9$ years; $S D=11.8$ ). The practitioners also self-reported that the mean frequency of the practice of martial arts was 2.0 days per week $(S D=1.7)$, which corresponded to $188.7 \mathrm{~min}$ per week on average $(S D=152.5)$. Representatives of the two groups and/or the researcher (Hiromitsu Miyata) asked all members of the two groups to participate in the study, unless these members no longer engaged in practice of martial arts at the time of the survey. Distribution and collection of the questionnaires were carried out either by using questionnaires printed on $\mathrm{A} 4$ paper or via an e-mail.

In addition, 66 healthy non-practitioners of martial arts (22 females and 44 males; age, 22-67 years; mean age $=44.5$ years,$S D=11.6$ ) participated as a control group. Data collection for these participants were conducted after the survey for the practitioners had been completed. On the basis of their self-reports, none of these non-practitioners practiced martial arts nor engaged in other relevant contemplative/mind-body practices including Zen, yoga, etc. According to previous studies $[10,12]$, data collection for the non-practitioners was performed by using "i Research," i.e., an online survey system by NEO Marketing Inc., Tokyo, Japan. In this system, there were approximately 6,390,000 monitors in Japan who had agreed to participate in multiple online questionnaire surveys by providing demographic information. Non-practitioners of marital arts were matched with practitioners of martial arts on demographic variables including sex (33\% females, 67\% males), age range (12\% in their twenties, $27 \%$ in their thirties, etc.), marital status (44\% married, 56\% unmarried), annual household income level (18\% below 2,000,000 Japanese yen, 36\% 2, 000,000-4,990,000 Japanese yen, 30\% 5,000,000-8,990, 000 Japanese yen, 3\% above 9,000,000 Japanese yen), and living area (Tokyo and the neighboring prefectures, Gunma, Shizuoka, Ishikawa, or Kyoto prefectures). Regarding household income level, the remaining $12 \%$ of the participants for both groups answered that they do not know their household income level. The survey included this option in order not to force all participants to report their income. Question items for the nonpractitioners were the same as those for the practitioners. Non-practitioners gave answers to the questions that appeared on an online survey display by checking relevant checkboxes. In the survey for the nonpractitioners, answers were required for all the question items, so that there were no items left unanswered.

\section{Psychological scales}

The survey for both groups included the Japanese versions of the psychological scales listed below. All these psychological scales had been developed and validated in the preceding studies, and had also been used in the preceding studies involving yoga practitioners [10] and speed-reading trainees [12]. Participants from both groups were notified that the aim of the study involved 
assessment of the normal psychological status of each participant and had nothing to do with evaluation or superiority/inferiority of any individual. Also, participants from neither group were notified that the study compared practitioners and non-practitioners of martial arts. In addition, the survey instructed participants to always give plain and honest answers. Another psychological scale on state-trait anxiety was included in the survey, the data for which were not analyzed due to technical errors in the instructions/question items.

\section{Five facet mindfulness questionnaire (FFMQ)}

The FFMQ [25] is one of the most commonly used psychological scales to measure dispositional mindfulness. The scale involves five core dimensions of mindfulness (facets/subscales), i.e., observing, describing, acting with awareness, non-judging of inner experience, and non-reactivity to inner experience. Each of the 39 items is rated on a five-point scale from 1 to 5. Sugiura et al. [26] developed and validated a Japanese version of the FFMQ by involving Japanese students, which was used in the present study. The present study expected that measures pertaining to martial arts should predict higher dispositional mindfulness, because martial arts are supposed to have similar correlates to mindfulness and/or Zen as well as sports.

\section{Subjective well-being scale (SWBS)}

The SWBS [27] is a psychological scale developed and validated in Japanese to measure core components of subjective well-being (see also $[28,29]$ for former versions of the scale). The SWBS has 15 items, each rated on a four-point scale from 1 to 4 . These items are classified into the five subscales each containing three items: general well-being - positive affect, confidence in coping, expectation-achievement congruence, general well-being - negative affect, and transcendence. The present study again expected that practice of martial arts should predict higher subjective well-being, based on the preceding studies suggesting that dispositional mindfulness is positively associated with psychological well-being ([30, 31]; see also $[10,12])$,

\section{Beck depression inventory (BDI)}

The BDI $[32,33]$ is one of the common classical measures of depression. The BDI has 21 items, each concerning core symptoms of depression, which are summed to calculate a total score. Each item has four self-evaluative sentences as options, each being scored from 0 to 3 . For each item, participants were instructed to select a sentence that best described how they recently felt. The present study used a validated Japanese version of the BDI $[34,35]$. Similar to the above, we expected that practice of martial arts should predict lower depression, because increase in dispositional mindfulness has been suggested to improve psychological health $[31,36]$.

\section{Statistical analysis methods}

All statistical analyses were conducted by using SPSS Statistics 25.0 software. Data for all participants from the two groups were included in the analysis. The initial analyses involved a description of outcomes from the psychological scales and comparisons between the groups. After calculation of total scores for the FFMQ, SWBS, and BDI as well as subscale (facet) scores for the FFMQ and SWBS for each group, independent samples $t$-tests were used to compare the two groups for all these total/subscale scores. As a measure of internal consistency, Cronbach's alphas ( $\alpha s)$ were examined for each group and total/subscale score. Items that were left blank for these psychological scales accounted for 0.16$3.64 \%$ for the practitioners and $0.00 \%$ for the nonpractitioners. Unavailable data for the practitioners were not included in the analysis. Also, to indicate how scores from each scale are associated with each other, Pearson's correlation coefficients ( $r$ values) were calculated between the total scores from the FFMQ, SWBS, and BDI. These correlation analyses were conducted separately for each group.

Next, we examined whether and how practice and/or expertise in martial arts would be correlated with psychological outcomes among the group of practitioners. To indicate practice/expertise in martial arts, the following self-reported measures were considered. (1) The Dan/Kyu rank refers to the rank or grade used to indicate each practitioner's degree or level of expertise within each practice of martial arts. The organizations to which participants in the present study belonged had multiple original Dan/Kyu grading systems (e.g., 5th to 1st Dans and 1st to 10th Kyus from higher to lower ranks in bojutsu), and multiple practitioners selfreported that they held two or more different Dans and/ or Kyus at the time of the survey. Thus, in the present study these practitioners were categorized according to whether s/he held the Dan rank(s) in either of the ranking systems, held only the Kyu rank(s), or held neither of these ranks $(2=$ Dan holder, $1=$ Kyu holder, $0=$ nonDan/Kyu holder). Spearman's rank correlation coefficients ( $r_{s}$ values) were calculated to indicate zero-order correlations between the Dan/Kyu rank and total/subscale scores from the psychological scales. (2) The practice period indicates the length of time (months) elapsed since the practitioner started to practice marital arts. (3) The practice frequency is the number of days in which each participant engaged in the practice of martial arts per week. Finally, (4) the practice time points to the total length of practice of marital arts in minutes per week for 
each practitioner. Regarding the latter three measures, Pearson's correlation coefficients were examined among the practitioners to look for correlations between practice in martial arts and psychological outcomes. When reporting practice frequency and practice time, four practitioners noted that meditation was included in the specific content of daily practice (frequency or time for meditation were not reported separately). The remaining content of practice for all the practitioners, i.e., swordsmanship, karate, bojutsu, etc., all involved body movements as in sports. To analyze elements of practice comparable to sports, values for these two measures from these four practitioners were excluded from analysis. Distributions for these three measures were positively skewed (skewness $=0.36$ for practice period, 1.48 for practice frequency, and 1.31 for practice time), showing that numbers of relatively extensive practitioners were small. Thus, data for these measures were log transformed (base 10) for this and subsequent statistical analyses to reduce the skewness.

Because multiple measures pertaining to martial arts showed statistically significant correlations with the total/subscale scores from the psychological scales, multiple regression analyses using a stepwise method were further conducted with each total/subscale score as a dependent variable. These analyses again involved the group of practitioners, and were conducted for scales/ subscales in which at least one measure pertaining to martial arts showed a statistically significant correlation with the scores. These analyses primarily intended to consider the potential influence of demographic variables on the scores from the psychological scales. In addition to the abovementioned four measures relevant to martial arts, we entered the following demographic variables as independent variables in a stepwise manner: sex $(0=$ male, $1=$ female $)$, age (years), marital status $(0=$ married, $1=$ unmarried), and annual household income level $(1$ = below 2,000,000 Japanese yen, $2=2,000,000-4$, 990,000 Japanese yen, $3=5,000,000-8,990,000$ Japanese yen, $4=$ above $9,000,000$ Japanese yen).

\section{Results}

Reliability, descriptive statistics, and group comparisons Cronbach's alpha values for both groups of participants showed overall good to acceptable reliability for the total/subscale scores from the psychological scales, even though alpha values were low for some subscale scores (e.g., $\alpha=0.48$ for the expectationachievement congruence subscale scores from the SWBS for the practitioners). Table 1 summarizes mean total/subscale scores from the psychological scales for each group of participants and comparisons between groups. For the FFMQ, the total and two subscale scores, i.e., observing and non-reactivity, were significantly higher for the practitioners than for the non-practitioners. We found no statistically significant difference between groups for the remaining three subscales. Regarding the SWBS, the total and all five subscale scores were significantly higher for the practitioners than for the non-practitioners. In contrast, total scores of the BDI were significantly lower for the practitioners than for the non-practitioners. Thus, practitioners of martial arts self-reported significantly higher mindfulness and subjective well-being and lower depression compared with the nonpractitioners.

Table 1 Descriptive statistics and comparisons between groups for each psychological scale

\begin{tabular}{|c|c|c|c|c|c|c|}
\hline & \multicolumn{2}{|c|}{ Practitioners $(N=33)$} & \multicolumn{2}{|c|}{ Non-Practitioners $(N=66)$} & \multicolumn{2}{|c|}{ Comparisons: Practitioners vs. Non-Practitioners } \\
\hline & $a$ & Mean $(S D)$ & $a$ & Mean $(S D)$ & $t(p)$ & Cohen's $d$ \\
\hline FFMQ Total & 0.91 & $130.39(17.97)$ & 0.78 & $119.14(12.99)$ & $3.078\left(0.004^{* *}\right)$ & 0.76 \\
\hline Observing & 0.76 & $27.61(4.88)$ & 0.87 & $20.70(5.85)$ & $5.787\left(<0.001^{* * *}\right)$ & 1.25 \\
\hline Describing & 0.78 & $23.94(4.59)$ & 0.73 & $23.83(4.76)$ & $0.105(0.917)$ & 0.02 \\
\hline Acting with Awareness & 0.71 & $27.48(4.30)$ & 0.89 & $28.52(6.04)$ & $-0.950(0.345)$ & 0.19 \\
\hline Non-Judging & 0.88 & $27.94(6.35)$ & 0.92 & $26.85(6.86)$ & $0.757(0.451)$ & 0.16 \\
\hline Non-Reactivity & 0.84 & $23.61(4.98)$ & 0.85 & $19.24(5.32)$ & $3.888\left(<0.001^{* * *}\right)$ & 0.84 \\
\hline SWBS Total & 0.90 & $45.97(7.30)$ & 0.93 & $35.65(9.29)$ & $5.317\left(<0.001^{* * *}\right)$ & 1.19 \\
\hline General Well-Being: Positive Affect & 0.83 & $10.43(1.50)$ & 0.87 & $7.62(2.32)$ & $7.024\left(<0.001^{* * *}\right)$ & 1.35 \\
\hline Confidence in Coping & 0.90 & $9.06(2.24)$ & 0.88 & $7.97(2.24)$ & $2.246\left(0.027^{*}\right)$ & 0.49 \\
\hline Expectation-Achievement Congruence & 0.48 & $8.42(1.34)$ & 0.82 & $6.79(2.40)$ & $4.233\left(<0.001^{* * *}\right)$ & 0.77 \\
\hline General Well-Being: Negative Affect ${ }^{a}$ & 0.79 & $9.44(2.18)$ & 0.82 & $6.64(2.23)$ & $5.809\left(<0.001^{* * *}\right)$ & 1.26 \\
\hline Transcendence & 0.77 & $8.81(1.93)$ & 0.74 & $6.64(2.06)$ & $4.948\left(<0.001^{* * *}\right)$ & 1.08 \\
\hline BDI Total & 0.91 & $9.25(9.16)$ & 0.92 & $13.79(11.02)$ & $-1.996\left(0.049^{*}\right)$ & 0.43 \\
\hline
\end{tabular}

Mean total/subscale scores and their standard deviations (SDs) are shown for each scale. ${ }^{*}: p<0.05 ;{ }^{* *}: p<0.01 ;{ }^{* * *}: p<0.001$

${ }^{a}$ : Higher scores show that less negative affect was self-reported 


\section{Correlations between scales}

For the practitioners of martial arts, total scores of the FFMQ were significantly and positively correlated with total scores of the SWBS $(r=0.733, p<0.001)$, and negatively with total scores of the BDI $(r=-0.626, p<0.001)$. Total scores of the SWBS and the BDI showed a significant negative correlation as well $(r=-0.820, p<0.001)$. These correlation trends between the total scores were generally similar for the non-practitioners, i.e., between the FFMQ and the SWBS $(r=0.540, p<0.001)$, between the FFMQ and the BDI $(r=-0.494, p<0.001)$, and between the SWBS and the BDI $(r=-0.739, p<0.001)$. These data show that desirable and non-desirable psychological functions are associated with each other, not only for those practicing martial arts but also for those with no daily practice of martial arts or meditation.

\section{Measures pertaining to martial arts and psychological outcomes}

Among the measures pertaining to practice/expertise in martial arts, the Dan/Kyu rank showed significant positive correlations with the practice period $\left(r_{s}=0.776, p<\right.$ $0.001)$, practice frequency $\left(r_{s}=0.604, p=0.0011\right)$, and practice time $\left(r_{s}=0.633, p<0.001\right)$. Also, the practice period showed a significant positive correlation with practice frequency $(r=0.484, p=0.011)$, but not with practice time $(r=0.367, p=0.066)$. Practice frequency and practice time were significantly and positively correlated with each other $(r=0.663, p<0.001)$. Thus, multiple parameters of martial arts were significantly associated with each other.
For the group of practitioners, Table 2 shows correlation coefficients between measures pertaining to practice/expertise in martial arts and total/subscale scores from the psychological scales. The Dan/Kyu rank showed significant positive correlations with the total scores of the FFMQ and two subscale scores of the SWBS, i.e., general well-being - positive affect and general well-being - negative affect, although correlations failed to reach statistical significance for the other total/ subscale scores. The practice period was significantly and positively correlated with the total FFMQ scores and two of its subscales, i.e., observing and describing, positively correlated with the total and all five subscale scores of the SWBS, and negatively correlated with the total score of the BDI (see also Fig. 1 for scatterplots depicted for the total scores). Practice frequency showed significant positive correlations with the total scores of the SWBS and its subscale, i.e., general well-being negative affect, and a significant negative correlation with the total score of the BDI; correlations were not statistically significant for the remaining total/subscale scores. In contrast, practice time failed to show statistically significant correlations with any of the total/subscale scores from the psychological scales. These data show that certified ranks showing expertise in martial arts, as well as the length of the practice period and (to a lesser extent) frequency of daily practice, were significantly associated with dimensions of mindfulness and psychological health among practitioners of martial arts.

Results obtained from further multiple regression analyses are summarized in Tables 3 and 4. Regarding the total scores from each scale as shown in Table 3, a

Table 2 Zero-order correlations between measures of practice/expertise and total/subscale scores from the psychological scales among practitioners of martial arts

\begin{tabular}{lllll}
\hline & Dan/Kyu Rank & $\begin{array}{l}\text { Practice Period } \\
\text { (months) }\end{array}$ & $\begin{array}{l}\text { Practice Frequency } \\
\text { (day per week) }\end{array}$ & $\begin{array}{l}\text { Practice Time } \\
\text { (min per week) }\end{array}$ \\
\hline FFMQ Total & $.398^{*}$ & $.493^{* *}$ & .123 & -.027 \\
Observing & .199 & $.383^{*}$ & -.094 & -.094 \\
Describing & .212 & $.438^{*}$ & .142 & -.114 \\
Acting with Awareness & .269 & .288 & .023 & .168 \\
Non-Judging & .292 & .324 & .230 & -.024 \\
Non-Reactivity & .286 & .279 & .131 & -.014 \\
SWBS Total & .331 & $.602^{* * *}$ & $.435^{*}$ & .306 \\
General Well-Being: Positive Affect & $.521^{* *}$ & $.578^{* *}$ & .367 & .267 \\
Confidence in Coping & .162 & $.375^{*}$ & .264 & .096 \\
Expectation-Achievement Congruence & .296 & $.449^{*}$ & .168 & .129 \\
General Well-Being: Negative Affect & & $.522^{* *}$ & $.436^{*}$ & .056 \\
Transcendence & $.468^{* *}$ & $.550^{* *}$ & .280 & .263 \\
BDI Total & .339 & $-.463^{* *}$ & $-.504^{* *}$ & -.352 \\
\hline
\end{tabular}

For the Dan/Kyu rank, Spearman's rank correlation coefficients ( $r_{s}$ values) are shown for each comparison. For the other three measures of practice, Pearson's correlation coefficients ( $r$ values) are shown. ${ }^{*}: p<0.05 ;{ }^{* *}: p<0.01 ;{ }^{* * *}: p<0.001$

${ }^{a}$ : Higher scores show that less negative affect was self-reported 

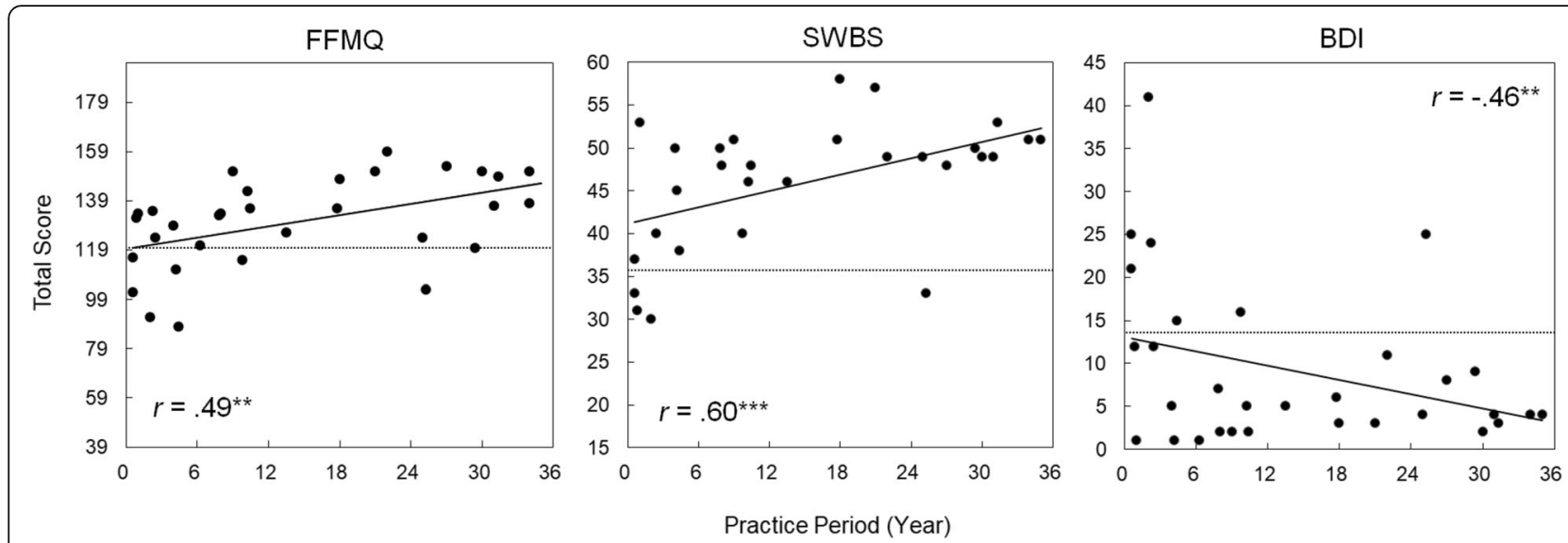

Fig. 1 Scatterplots showing correlations between the practice period in years and total scores from each psychological scale, plotted for each practitioner of marital arts. Dotted lines show mean total scores for the non-practitioners. R: Pearson's correlation coefficient. ${ }^{* *}: p<0.01$; ***: $p<0.001$

longer practice period significantly predicted higher scores of the FFMQ $\left(R^{2}=0.272, B=20.118, S E=7.983\right.$, $\beta=0.522, t=2.520, p=0.022$ ). Also, a higher practice frequency significantly predicted lower total scores of the BDI $\left(R^{2}=0.213, B=-14.044, S E=6.542, \beta=-0.462\right.$, $t=-2.147, p=0.047)$. Regarding the subscale scores as shown in Table 4, a longer practice period significantly predicted higher scores for the describing subscale from the FFMQ $\left(R^{2}=0.443, B=5.672, S E=1.541, \beta=0.666\right.$, $t=3.681, p=0.002$ ). Also, a higher practice frequency significantly predicted higher scores on the general wellbeing - negative affect subscale from the SWBS $\left(R^{2}=\right.$ $0.246, \quad B=2.926, \quad S E=1.243, \quad \beta=0.496, \quad t=2.355, \quad p=$

Table 3 Results of the multiple regression analyses conducted for the total scores from each psychological scale

\begin{tabular}{|c|c|c|c|c|c|c|}
\hline \multirow{2}{*}{$\begin{array}{l}\text { Independent } \\
\text { variable }\end{array}$} & \multicolumn{3}{|l|}{ FFMQ } & \multicolumn{3}{|l|}{ BDI } \\
\hline & $\beta$ & $t$ & VIF & $\beta$ & $t$ & VIF \\
\hline (Constant) & - & $5.063^{* * *}$ & - & - & $4.726^{* * *}$ & - \\
\hline \multicolumn{7}{|l|}{ Demographic variables } \\
\hline Sex & .146 & .667 & 1.081 & -.130 & -.508 & 1.352 \\
\hline Age & .148 & .658 & 1.144 & -.206 & -.947 & 1.016 \\
\hline Marital status & -.060 & -.221 & 1.601 & .179 & .751 & 1.199 \\
\hline Household income & .152 & .722 & 1.000 & -.365 & -1.806 & 1.000 \\
\hline \multicolumn{7}{|c|}{ Practice/expertise in martial arts } \\
\hline Dan/Kyu rank & -.399 & -1.291 & 2.320 & .042 & .168 & 1.271 \\
\hline Practice period & .522 & $2.520^{*}$ & 1.000 & -.264 & -1.096 & 1.268 \\
\hline Practice frequency & -.005 & -.022 & 1.268 & -.462 & $-2.147^{*}$ & 1.000 \\
\hline Practice time & -.122 & -.538 & 1.154 & .166 & .437 & 2.954 \\
\hline$R^{2}$ & .272 & & & .213 & & \\
\hline Adjusted $R^{2}$ & .229 & & & .167 & & \\
\hline$F$ & $6.351^{*}$ & & & $4.609^{*}$ & & \\
\hline
\end{tabular}

Variables removed from each model are shown in the table. * $p<0.05$; ***: $p<0.001$
0.031). Marital status, though not the remaining independent variables, significantly predicted scores on the transcendence subscale from the SWBS (scores were higher for those being married; $R^{2}=0.217, B=-1.833$, $S E=0.845, \beta=-0.466, t=-2.170, p=0.045)$. All other measures pertaining to martial arts and demographic variables were removed from these regression models (Tables 3 and 4 show beta coefficients when these variables were entered into the models). Variance Inflation Factor (VIF; a measure of multi-collinearity) proved to be 2.954 or smaller for all these regression models, indicating low multi-collinearity. With regard to the remaining subscales, no independent variables significantly predicted psychological outcomes. These data show that longer practice or higher frequency of daily practice of martial arts was significantly associated with higher dispositional mindfulness and dimensions of psychological health, even when multiple demographic variables were taken into account.

\section{Discussion}

Compared with non-practitioners, practitioners of martial arts self-reported answers that were calculated as significantly higher scores on mindfulness and subjective well-being and lower scores on depression. Among practitioners of martial arts, the practice period and (to a lesser extent) certified ranks of expertise (Dan/Kyu rank) as well as the frequency of daily practice were significantly correlated with higher mindfulness and psychological health outcomes. These associations between practice/expertise in martial arts and psychological outcomes were generally consistent after controlling for demographic variables, whereas a higher frequency of daily practice, but not a longer practice period, predicted lower depression. These data are overall consistent with the hypotheses and support the notion that continued 
Table 4 Results of the multiple regression analyses conducted for the subscale scores from each psychological scale

\begin{tabular}{|c|c|c|c|c|c|c|c|c|c|}
\hline \multirow{2}{*}{$\begin{array}{l}\text { Independent } \\
\text { variable }\end{array}$} & \multicolumn{3}{|c|}{ FFMQ: Describing } & \multicolumn{3}{|c|}{ SWBS: General Well-Being-Negative Affect } & \multicolumn{3}{|c|}{ SWBS: Transcendence } \\
\hline & $\beta$ & $t$ & VIF & $\beta$ & $t$ & VIF & $\beta$ & $t$ & VIF \\
\hline (Constant) & - & $3.360^{* *}$ & - & - & $20.415^{* * *}$ & - & - & $8.231^{* * *}$ & - \\
\hline \multicolumn{10}{|l|}{ Demographic variables } \\
\hline Sex & .303 & 1.695 & 1.081 & .123 & .491 & 1.352 & .235 & 1.075 & 1.046 \\
\hline Age & .131 & .667 & 1.144 & .201 & .944 & 1.016 & -.061 & -.262 & 1.106 \\
\hline Marital status & -.147 & -.632 & 1.601 & -.155 & -.663 & 1.199 & -.466 & $-2.170^{*}$ & 1.000 \\
\hline Household income & -.049 & -.265 & 1.000 & .275 & 1.334 & 1.000 & -.106 & -.481 & 1.000 \\
\hline \multicolumn{10}{|c|}{ Practice/expertise in martial arts } \\
\hline Dan/Kyu rank & -.309 & -1.130 & 2.320 & .124 & .511 & 1.271 & -.246 & -1.068 & 1.158 \\
\hline Practice period & .666 & $3.681^{* *}$ & 1.000 & .282 & 1.205 & 1.268 & .016 & .057 & 1.601 \\
\hline Practice frequency & -.114 & -.548 & 1.268 & .496 & $2.355^{*}$ & 1.000 & .259 & 1.110 & 1.199 \\
\hline Practice time & -.036 & -.180 & 1.154 & -.278 & -.757 & 2.954 & .335 & 1.543 & 1.108 \\
\hline$R^{2}$ & .443 & & & .246 & & & .217 & & \\
\hline Adjusted $R^{2}$ & .411 & & & .202 & & & .171 & & \\
\hline F & $13.547^{* *}$ & & & $5.544^{*}$ & & & $4.707^{*}$ & & \\
\hline
\end{tabular}

Variables removed from each model are shown in the table. ${ }^{*}: p<0.05 ;{ }^{* *}: p<0.01 ;{ }^{* * *}: p<0.001$

practice as well as the degree of expertise are associated with higher dispositional mindfulness and desirable psychological status among a population of practitioners of Japanese marital arts.

Results obtained from the present study seem to be consistent with the nature of martial arts. That is, Japanese traditional martial arts are considered not only to involve elements of sports including physical exercise, but also to have close connections with Zen Buddhism $[16,17]$. For example, martial arts stresses the importance of both interoceptive and exteroceptive awareness. Such characteristics also seem to overlap with essential components of mindfulness [25, 26]. Also, the present data are generally consistent with those previously obtained for other populations of practitioners of mindbody or contemplative practices in Japan. That is, both yoga practitioners [10] and trainees of meditation-based speed-reading [12] self-reported higher mindfulness and psychological health associated with the period of practice and/or attained stages of expertise. Considering the present data together with those from preceding studies, we could suggest that practice of multiple Eastern mindbody practices might be associated with similar psychological outcomes including higher mindfulness and psychological health. The results also seem important in that they support the view that mind-body practices based on traditions are associated with higher trait mindfulness and psychological health even with no explicit emphasis on mindfulness as in the MBSR [6,7] or MBCT [8] programs.

Despite these novelties and perspectives, the present study does have important limitations. The first concerns the cross-sectional design of the study. With the present data alone, there could be a counterargument that long-term practitioners had exhibited higher mindfulness and psychological health since before they started the practice of martial arts. Also, the practitioners and non-practitioners in the present study were matched on observable demographic variables alone. It could potentially be possible that differences in mental attitudes and/or psychological characteristics that were not explicitly observed (e.g., general motivational states before starting practice) may have heightened the probability of practicing martial arts among the population of practitioners. These issues are difficult to be resolved by using a cross-sectional design. To overcome these limitations, one potential next step would be to conduct a longitudinal study to follow each practitioner for at least several months or years. For example, including university students who practice marital arts as an extracurricular activity is feasible, because this approach would enable systematic tracing of each practitioner for at least several years. In addition, it should be ideal if we could randomly assign non-practitioners to the practice group and the control group, and follow the same populations for years or even decades by using a longitudinal design. However, these long-term longitudinal studies are impractical, if not impossible to conduct. In this sense, a cross-sectional design also seems to make a significant sense. As indicated in preceding studies [2, 10, 12], a cross-sectional design enables involvement of large numbers of long-term practitioners and highly advanced experts to uncover their psychological, somatic physiological, and/or neurocognitive processes. As noted 
in the Introduction, use of this design is also useful when first studying a certain population of practitioners.

A second and related issue is that we failed to study sufficient numbers of practitioners to conduct structural equation modeling analyses (e.g., [12]). This may explain why causal relationships between the practice of martial arts and mindfulness and psychological health were not determined more convincingly. Because collecting data from larger numbers of practitioners from the studied populations was practically difficult, involving multiple populations of practitioners who practice different styles of martial arts would be more preferable. Such a widened survey should enable assessment of both similar and different aspects of psychological status between multiple populations of practitioners, and contribute to heightened degrees of external validity. These approaches seem particularly interesting considering the fact that traditional martial arts in Japan have many schools with both commonalities and differences in their practice styles [16].

\section{Conclusions}

Taken together, to the best of our knowledge, the present study is the first to demonstrate dispositional mindfulness and psychological health in a population of continued practitioners of martial arts based on Japanese traditions. Similarity of the present results to those previously obtained in other Japanese practitioners of mindbody or contemplative practices would support the notion that continued practice of multiple Eastern mindbody practices may be associated with higher dispositional mindfulness and psychological health outcomes. Based on these findings, future studies may examine various dimensions of psychological, behavioral, and physiological correlates of martial arts. Comparable to mindfulness training [6-8], martial arts essentially emphasize the importance of attention to one's own breath and body, and awareness of both the internal and external environments. Introduction of a task to assess interoceptive awareness such as a heartbeat detection task [37] and a water load test [38] combined with behavioral tasks of attention will be promising to examine how performance on these tasks are associated with expertise in marital arts. Because martial arts involve quick, balanced, and flexible body movements as well as mindfulness $[16,18]$, investigating how mindfulness and psychological statuses may be coupled with capabilities of body balance and coordination among the practitioners will also be challenging [19]. Because many of these components of martial arts seem to overlap with those of sports, making direct comparisons between martial arts and sports by using the same research paradigms should be an important frontier as well.
From a theoretical perspective, Eastern thoughts on mind and body have assumed that mind-body integration and unity should be sought for through physical/ mental practices, as termed Shin-Shin Ichinyo (body and mind as one) [3]. This seems to also go in line with KenZen Ichinyo (oneness of Zen and swordsmanship) as has been worded in the traditions of martial arts [17]. Such traditional words seem to represent Japanese forms of mindfulness, and could potentially be well understood within the modern scientific framework of mindfulness. Abovementioned various empirical studies should promisingly contribute to this exciting literature, and lead to an integrated understanding of the traditional mindbody theory in the East and the modern spirituality developed in Western countries.

\section{Abbreviations}

BDI: Beck Depression Inventory; FFMQ: Five Facet Mindfulness Questionnaire; MBCT: Mindfulness-Based Cognitive Therapy; MBSR: Mindfulness-Based Stress Reduction; SWBS: Subjective Well-Being Scale

\section{Acknowledgements \\ The authors would like to thank Hiroyuki Aoki and Akiko Yoshida, Tenshinkai (General Incorporated Foundation), and Akira Watari, NPO Tenshintaido, and Takahiko Maruyama, Faculty of Letters, Arts and Sciences, Waseda University, for their assistance in recruiting the participants and for useful advice about drafting the survey sheets.}

\section{Authors' contributions}

HM1 conceived and designed the study, collected, analyzed, and interpreted the data, and wrote the paper. DK, AS, HM2, and SA analyzed and interpreted the data and drafted a previous version of the paper. All authors read and approved the final manuscript.

\section{Funding}

This research was supported by Waseda University Grants for Special Research Projects (Project numbers: 2018A-005 and 2019E-016) and by JSPS KAKENHI Grant Number JP18K03187. The funders had no role in the study design, data collection, analysis, and interpretation, decision to publish, or in writing of the manuscript.

\section{Availability of data and materials}

The datasets used and/or analyzed during the study are available from the corresponding author upon reasonable request.

\section{Ethics approval and consent to participate}

The study was approved by the Ethics Review Committee on Research with Human Subjects of Waseda University (Approval No. 2018-218). All practitioners of martial arts gave written informed consent upon agreement to participate. All non-practitioners checked a box on the online survey to indicate agreement to participate, immediately before starting the survey.

\section{Consent for publication}

All participants provided informed consent to have their anonymized information published.

\section{Competing interests}

The authors declare that they have no competing interests.

Received: 28 May 2020 Accepted: 2 December 2020

Published online: 07 December 2020

\section{References}

1. Goyal M, Singh S, Sibinga EMS, Gould NF, Rowland-Seymour A, Sharma R, et al. Meditation programs for psychological stress and well-being: a systematic review and meta-analysis. JAMA Intern Med. 2014;174(3):357-68. 
2. Slagter HA, Davidson RJ, Lutz A. Mental training as a tool in the neuroscientific study of brain and cognitive plasticity. Front Hum Neurosci. 2011;5(17). https://doi.org/10.3389/fnhum.2011.00017.

3. Yuasa Y. The body: toward an eastern mind-body theory. New York: SUNY Press; 1987.

4. Baer RA. Mindfulness training as a clinical intervention: a conceptual and empirical review. Clin Psychol Sci Pract. 2003;10(2):125-43.

5. Hofmann SG, Sawyer AT, Witt AA, Oh D. The effect of mindfulness-based therapy on anxiety and depression: a meta-analytic review. J Consult Clin Psychol. 2010;78(2):169-83.

6. Kabat-Zinn J. An out-patient program in behavioral medicine for chronic pain patients based on the practice mindfulness meditation: theoretical considerations and preliminary results. Gen Hosp Psychiatry. 1982;4(1):33-47.

7. Kabat-Zinn J. Full catastrophe living: using the wisdom of your body and mind to face stress, pain and illness. New York: Delacorte; 1990.

8. Segal ZV, Williams JMG, Teasdale JD. Mindfulness-based cognitive therapy for depression: a new approach to preventing relapse. New York: Guilford; 2002.

9. Kuyken W, Nuthall E, Byford S, Crane C, Dalgleish T, Ford T, et al. The effectiveness and cost-effectiveness of a mindfulness training programme in schools compared with normal school provision (MYRIAD): study protocol for a randomised controlled trial. Trial. 2017;18(1):194. https://doi.org/10. 1186/s13063-017-1917-4.

10. Miyata H, Okanoya K, Kawai N. Mindfulness and psychological status of Japanese yoga practitioners: a cross-sectional study. Mindfulness. 2015;6(3): 560-71.

11. Miyata $\mathrm{H}$. A preliminary analysis on the autonomic nervous system activities during meditation by a yoga expert (report no. JCSS-TR-77). Kawasaki: Japanese Cognitive Science Society; 2018

12. Miyata H, Sasaki T. The park-Sasaki method of speed-reading and mindfulness: a cross-sectional study. WASEDA RILAS J. 2019;7:235-48.

13. Miyata H. Psychological studies of speed-reading as a contemplative training method. AGU J Psychol. 2015;15:77-90.

14. Miyata H, Minagawa-Kawai Y, Watanabe S, Sasaki T, Ueda K. Reading speed, comprehension and eye movements while reading Japanese novels: evidence from untrained readers and cases of speed-reading trainees. PLoS One. 2012;7(5):e36091. https://doi.org/10.1371/journal.pone.0036091.

15. Miyata H, Watanabe S, Ueda K, Sasaki T, Minagawa Y. Enhanced visual form and visuo-spatial processes in Japanese speed-reading experts: a preliminary analysis (report no. JCSS-TR-74). Nagoya: Japanese Cognitive Science Society; 2016.

16. Yukawa S. Karate to Zen: shitai-shinrigaku de budo wo kaimei! Mindfulness ga michibiku "zen-houiteki-ishiki" he (karate and Zen: elucidating martial arts by embodied psychology! Towards an "awareness to all directions" guided by mindfulness). Tokyo: BAB Japan; 2014. (in Japanese).

17. Kasai A. Ken Zen Ichinyo shiso no genryu: Takuan to Yagyu Shinkage Ryu (the source of ken Zen Ichinyo though0)t: Takuan and the Yagyu Shinkage school. J Indian Buddhist Stud. 2006:55(1):230-4 (in Japanese).

18. Burschka JM, Kuhn P, Menge U, Oschmann P. Research on tai chi as a sport in health care. Sportwiss. 2013:43(3):181-96.

19. Burschka JM, Keune PM, Oy UH, Oschmann P, Kuhn P. Mindfulness-based interventions in multiple sclerosis: beneficial effects of tai chi on balance, coordination, fatigue and depression. BMC Neurol. 2014;14(165):1-9.

20. Wang C, Schmid CH, Fielding RA, Harvey WF, Reid KF. Effect of tai chi versus aerobic exercise for fibromyalgia: comparative effectiveness randomized controlled trial. BMJ. 2018;360:k851. https://doi.org/10.1136/bmj.k851.

21. Shin JH, Lee Y, Kim SG, Choi BY, Lee HS, Bang SY. The beneficial effects of tai chi exercise on endothelial function and arterial stiffness in elderly women with rheumatoid arthritis. Arthritis Res Ther. 2015;17:380. https://doi. org/10.1186/s13075-015-0893-x.

22. Tanaka M, Yamamoto M, Kokubo H, Kokado T, Zhang T, Parkhomtchouk DV et al. ECG analysis in a remote action experiment. J Intl Soc Life Info Sci. 2001;19(2):466-72

23. Kawano K. Special abilities with EEGs. Jpn J Parapsychol. 2005;10(1, 2):41-5 (in Japanese).

24. Aoki H. Tenshin Shiso (thoughts of Tenshin). Tokyo: Tenshinkai; 2017

25. Baer RA, Smith GT, Hopkins J, Krietemeyer J, Toney L. Using self-report assessment methods to explore facets of mindfulness. Assessment. 2006; 13(1):27-45.

26. Sugiura $Y$, Sato A, Ito Y, Murakami H. Development and validation of the Japanese version of the five facet mindfulness questionnaire. Mindfulness. 2012;3(2):85-94.
27. Ito $Y$, Sagara J, Ikeda M, Kawaura Y. Reliability and validity of subjective wellbeing scale. Jpn J Psychol. 2003;74(3):276-81 (in Japanese).

28. Sell H, Nagpal R. Assessment of subjective well-being: the subjective wellbeing inventory (SUBI). Regional Office for South-East Asia, World Health Organization: New Delhi; 1992.

29. Tonan K, Sonoda A, Ono Y. Production of the subjective well-being inventory Japanese edition: its reliability and validity. Jpn J Health Psychol. 1995:8(2):12-9 (in Japanese).

30. Baer RA, Smith GT, Lykins E, Button D, Krietemeyer J, Sauer S, et al. Construct validity of the five facet mindfulness questionnaire in meditating and nonmeditating samples. Assessment. 2008;15(3):329-42.

31. Shapiro SL, Schwartz GER, Santerre C. Meditation and positive psychology In: Snyder CR, Lopez SJ, editors. Handbook of positive psychology. New York: Oxford University Press; 2002. p. 632-45.

32. Beck AT, Ward CH, Mendelson M, Mock JE, Erbaugh JK. An inventory for measuring depression. Arch Gen Psychiatry. 1961;4:561-71.

33. Beck AT, Rush AJ, Shaw BF, Emery G. Cognitive therapy of depression. New York: Guilford Press; 1979.

34. Hayashi K. Study on depressive states of students based on Beck's cognitive therapy. Stud Counsel J. 1988;9(2):97-10.7 (in Japanese).

35. Hayashi K, Takimoto T. An examination of Beck depression inventory (1978) and an analysis of relation between depressive tendencies and grade of self-efficacy. Memoires Shiraumegakuen College. 1991;27:43-52 (in Japanese)

36. Carmody J, Baer RA. Relationships between mindfulness practice and levels of mindfulness, medical and psychological symptoms and well-being in a mindfulness-based stress reduction program. J Behav Med. 2008;31(1):23-33.

37. Schandry R. Heart beat perception and emotional experience. Psychophysiology. 1981;18(4):483-8.

38. Herbert BM, Muth ER, Pollatos O, Herbert C. Interoception across modalities: on the relationship between cardiac awareness and the sensitivity for gastric functions. PLoS One. 2012;7(5):e36646. https://doi.org/10.1371/ journal.pone.0036646.

\section{Publisher's Note}

Springer Nature remains neutral with regard to jurisdictional claims in published maps and institutional affiliations.
Ready to submit your research? Choose BMC and benefit from:

- fast, convenient online submission

- thorough peer review by experienced researchers in your field

- rapid publication on acceptance

- support for research data, including large and complex data types

- gold Open Access which fosters wider collaboration and increased citations

- maximum visibility for your research: over $100 \mathrm{M}$ website views per year

At $\mathrm{BMC}$, research is always in progress.

Learn more biomedcentral.com/submissions 